\title{
Desenvolvimento de sorvetes à base de caldo de cana e avaliação sensorial com crianças
}

\section{Development of ice cream based sugar cane juice and sensory evaluation with children}

\author{
Vanessa Pedro da Silva ${ }^{1 *}$; Dayana do Nascimento Ferreira ${ }^{1}$; \\ Nayara Gabriela Gonçalves de Souza²; Anatalha Marinho Alexandre²; \\ Isrrael Felix Alves Gomes' ${ }^{2}$; Ricardo Targino Moreira ${ }^{3}$
}

\section{Resumo}

O sorvete é um alimento saboroso e nutritivo, fonte de proteínas e cálcio, mas deficiente em alguns minerais como o ferro, presente no caldo de cana que é fonte de minerais, como ferro, fósforo, cálcio, sódio, entre outros. Objetivou-se com o presente trabalho desenvolver sorvetes com caldo de cana, com a finalidade de aumentar o teor de minerais substituindo o açúcar refinado e a água no processo de fabricação pelo caldo de cana; avaliar a sua composição físico-química; e verificar sua aceitação sensorial com crianças. Foram elaboradas três formulações dos sorvetes de caldo de cana: sorvete de caldo de cana (SC), sorvete de caldo de cana com mel de engenho (SCM) e sorvete de caldo de cana com rapadura (SCR). A avaliação sensorial foi realizada com 120 crianças (62 meninos e 58 meninas), com idades entre 8 e 10 anos, estudantes do $3^{\circ}$ ao $5^{\circ}$ ano do ensino fundamental. Foram aplicados os testes sensoriais de ordenação-preferência, intenção de consumo e aceitação com escala hedônica facial de 7 pontos. Os resultados das análises físico-químicas e teste de aceitação foram avaliados estatisticamente por análise de variância (ANOVA), as médias comparadas pelo teste de Tukey ( $\mathrm{p} \leq$ $0,05)$; e o resultado do teste de ordenação-preferência analisado pelo teste de Friedman. Os sorvetes desenvolvidos apresentaram reduzido teor de gordura, além de serem formulados com gordura de palma livre de trans. A utilização do caldo de cana na formulação dos sorvetes elevou a quantidade de minerais, quando comparado aos sorvetes comuns. Portanto, os sorvetes de caldo de cana demonstraram ser mais saudáveis e nutritivos, comparativamente aos sorvetes tradicionais, além de serem fonte de cálcio, ferro e fósforo; atendendo parte das necessidades de ingestão diária recomendada (IDR), para crianças de 7 a 10 anos. Quanto à avaliação sensorial; todas as formulações dos sorvetes de caldo de cana obtiveram ótima aceitação sensorial junto às crianças em todos os atributos sensoriais avaliados, apresentando excelentes porcentagens de aceitação e intenção de consumo pelas crianças.

Palavras-chave: Cálcio, ferro, minerais, nutritivo

\footnotetext{
Abstract

Ice cream is a tasty and nutritious source of protein and calcium, but it is deficient in some minerals, as iron, but it is found in sugar cane juice, which is a source of minerals such as iron, phosphorus, calcium, sodium among others. The objective of the present study are: to develop sugar cane juice ice cream, in order to increase the mineral content replacing refined sugar and water during the manufacturing

${ }^{1}$ Discentes do Programa de Pós-Graduação em Ciência e Tecnologia de Alimentos, Universidade Federal da Paraíba, UFPB, João Pessoa, PB. E-mail: vanessapsv@yahoo.com.br; dayreeves@hotmail.com

${ }^{2}$ Discentes do Curso de Engenharia de Alimentos, UFPB, João Pessoa, PB. E-mail: nayara-gabriela@hotmail.com; anatalhama@ gmail.com; isrrael.felix@gmail.com

${ }^{3}$ Prof. do Dept ${ }^{\circ}$ de Engenharia de Alimentos, UFPB, João Pessoa, PB. E-mail: ricardo.ufpb@gmail.com

* Autor para correspondência
} 
process by sugar cane juice; to analyze its physical-chemical composition; to check your sensory acceptance with children. Three formulations were prepared from sugar cane juice ice cream: sugar cane juice ice cream (SC), sugar cane juice ice cream with molasses (SCM) and sugar cane juice ice cream with brown sugar (SCR). Sensory evaluation was conducted with 120 children (62 boys and 58 girls) from 8 to 10 years old, students from 3rd to 5 th years of primary school. Sensory tests were ordering-preference, intention to use and acceptance with facial hedonic scale of 7 points. The results of physico-chemical and acceptance testing were statistically analyzed by analysis of variance (ANOVA), the scores compared by Tukey test $(\mathrm{p} \leq 0.05)$ and the result of the sensory test ordering-preference were assessed using the Friedman. The ice cream it presents has a reduced fat content because it was formulated with palm trans-fat free. The use of sugar cane juice in the formulation of the ice cream increased the amount of minerals when compared to ordinary ice cream. Therefore, sugar cane juice ice cream demonstrated to be more healthy and nutritious compared with traditional ice cream, besides being source of calcium, iron and phosphorus; serving the needs of the recommended daily intake (IDR) for children from 7 to 10 years old. About the sensory evaluation, all formulations of sugar cane juice ice cream obtained great sensory acceptance among children in all sensory attributes evaluated, showing excellent percentages of acceptance and intention to use by children.

Key words: Calcium, iron, minerals, nutritious

\section{Introdução}

Com as mudanças nos hábitos alimentares e a busca por um estilo de vida mais saudável, cresce a demanda por alimentos que aliem vários benefícios nutricionais. Em sorvetes, uma das formas de elevar o seu valor nutricional e o teor de minerais é adicionar frutas ou outros alimentos ricos nesses nutrientes.

O consumo de sorvete no Brasil cresceu 76,49\% entre os anos de 2003 e 2012 (ABIS, 2013). Em 2009, a produção de sorvetes, picolés e produtos gelados no Brasil foi de 341.471 toneladas, e o consumo de 345.513 toneladas (IBGE, 2009a). Segundo a Agência Nacional de Vigilância Sanitária, sorvete ou gelados comestíveis são os produtos congelados obtidos a partir de uma emulsão de gorduras e proteínas; ou de uma mistura de água e açúcar que podem ser adicionados de outros ingredientes desde que não descaracterizem o produto (BRASIL, 2005a). Por apresentar em sua composição nutrientes como proteína e cálcio, pode ser considerado um alimento nutritivo, fonte de energia.

A cana de açúcar (Sacharum ssp.) é composta por 65 a 75\% de água, 12 a 23\% de sólidos solúveis,
11 a $18 \%$ de açucares, 8 a $14 \%$ de fibras e 3 a $5 \%$ de minerais (REZZADORI, 2010). Seu principal componente é a sacarose, que corresponde de 70 a 91\% dos sólidos solúveis (NOGUEIRA et al., 2009). O caldo de cana conserva os nutrientes da cana de açúcar, entre eles os minerais (3 a 5\%) como ferro, cálcio, potássio, sódio, fósforo, magnésio e cloro (FAVA, 2004). Além de ser boa fonte de minerais, tem elevado teor de açúcar podendo substituir o açúcar refinado na produção de sorvete.

Unir os benefícios do caldo de cana que é um alimento nutritivo, fonte de minerais, com o sorvete, um alimento saboroso, acessível a todas as classes sociais e muito consumido por crianças, é proporcionar um sorvete saboroso, fonte de minerais, atendendo parte das necessidades nutricionais das crianças.

Objetivou-se com o presente trabalho desenvolver sorvetes com caldo de cana, com a finalidade de elaborar um sorvete mais saudável e nutritivo aumentando o teor de minerais com a substituição do açúcar refinado e da água no processo de fabricação pelo caldo de cana; avaliar a sua composição físico-química e verificar sua aceitação sensorial com crianças de 8 a 10 anos. 


\section{Material e Métodos}

\section{Material}

A cana de açúcar foi adquirida de um produtor rural do município de Santa Rita - PB. Foi recebida no Laboratório de Tecnologia de Alimentos (LTA), onde foi lavada com água potável, cortada, raspada, higienizada em banho com solução de hipoclorito de sódio a 200 ppm durante 20 minutos, lavada em água potável e moída para obtenção do caldo.

No processamento dos sorvetes foram utilizados os seguintes ingredientes: gordura de palma (Agropalma), leite em pó integral (Palate), soro de leite em pó desmineralizado (Primalatte), estabilizante (Sherex IC 8560 Kerry) e emulsificante (Duas Rodas), que foram doados pela indústria onde o sorvete foi processado, localizada no município de Cabedelo - PB. A rapadura (Olho d'cana) e o mel de engenho (Olho d'cana) foram adquiridos em mercado público municipal localizado no município de João Pessoa - PB.

\section{Formulação do sorvete de caldo de cana}

Os sorvetes foram elaborados de acordo com as formulações apresentadas (Tabela 1), utilizando como base principal de todas as formulações o caldo de cana. Foram produzidas três formulações: sorvete de caldo de cana (SC), sorvete de caldo de cana com mel de engenho (SCM) e sorvete de caldo de cana com rapadura (SCR), com três repetições do processamento para cada formulação.

Tabela 1. Ingredientes das formulações dos sorvetes de caldo de cana.

\begin{tabular}{cccc}
\hline Ingredientes & SC & SCM & SCR \\
\hline Caldo de cana & $81,0 \%$ & $78,0 \%$ & $78,0 \%$ \\
Rapadura & - & $\overline{3,0 \%}$ & $3,0 \%$ \\
Mel de engenho & $\overline{4,0 \%}$ & $4,0 \%$ & $\overline{4,0 \%}$ \\
Gordura de palma & $6,5 \%$ & $6,5 \%$ & $6,5 \%$ \\
Leite em pó integral & $6,5 \%$ & $6,5 \%$ & $6,5 \%$ \\
Soro de leite & $0,5 \%$ & $0,5 \%$ & $0,5 \%$ \\
Estabilizante & $1,5 \%$ & $1,5 \%$ & $1,5 \%$ \\
Emulsificante & & & \\
\hline
\end{tabular}

SC (sorvete de caldo de cana), SCM (sorvete de caldo de cana com mel de engenho), SCR (sorvete de caldo de cana com rapadura). Fonte: Elaboração dos autores.

\section{Processamento do sorvete de caldo de cana}

A produção das formulações do sorvete de caldo de cana foi realizada de acordo com a metodologia descrita por Galvão (2003) com algumas modificações. Para o preparo da calda base os ingredientes secos (leite em pó integral, soro de leite em pó, estabilizante e rapadura) foram pesados, os ingredientes líquidos e fluidos (caldo de cana, gordura de palma liquefeita e mel de engenho) foram medidos com o auxílio de provetas. Todos os ingredientes foram misturados e homogeneizados em liquidificador industrial, modelo LB 25 PMB, marca Siemsen Ltda por 5 minutos. A calda base produzida foi pasteurizada a $75^{\circ} \mathrm{C}$ por 15 minutos, resfriada a $4^{\circ} \mathrm{C}$ e maturada por 12 horas. Após essa etapa a calda base e o emulsificante foram colocados na máquina produtora de sorvete descontínua, modelo 12 LB, marca Inadal Indústria de Máquinas Ltda, para o congelamento e produção do sorvete. $\mathrm{O}$ sorvete produzido foi envasado em potes plásticos com capacidade para dois litros e acondicionados na câmara frigorífica a temperatura de $-21^{\circ} \mathrm{C}$. 


\section{Avaliação microbiológica}

Os sorvetes elaborados foram analisados de acordo comos padrõesmicrobiológicos estabelecidos pela RDC $\mathrm{n}^{\circ}$ 12, de 02 de janeiro de 2001 (BRASIL, 2001). As amostras foram submetidas às análises microbiológicas de contagem de coliformes totais e termotolerantes, Staphylococcus aureus coagulase positiva seguindo a metodologia descrita pela American Public Health Association (APHA, 2001), e Salmonella pela metodologia da Food and Drug Administration (FDA, 2011).

\section{Avaliação físico-química}

Os teores de umidade, cinzas e proteínas foram determinados utilizando a metodologia da AOAC (2000), com fator de correção de 6,38 para a análise de proteína. Os lipídios foram determinados pelo método de Bligh e Dyer (1959), utilizandose a metodologia descrita pelo Instituto Adolf Lutz (2008). Os carboidratos foram determinados por diferença. Foram determinados os açúcares redutores em lactose, açúcares não redutores em sacarose e açúcares totais, pela metodologia descrita pelo Instituto Adolf Lutz (2008), para gelados comestíveis à base de leite. $\mathrm{O}$ valor calórico total (VCT) foi determinado multiplicando-se o teor de lipídios por $9,0 \mathrm{kcal} / \mathrm{g}$, o teor de proteínas por
$4,0 \mathrm{kcal} / \mathrm{g}$ e o teor de carboidratos por $4,0 \mathrm{kcal} / \mathrm{g}$. Foram determinados os minerais cálcio, ferro, fósforo e sódio, pela técnica de espectrofotometria de absorção atômica em aparelho espectrofotômetro Varian, modelo Spectr AA-200 VARIAN (AOAC, 2000) realizado na Universidade Federal de Viçosa.

\section{Avaliação sensorial}

A avaliação sensorial foi realizada com 120 crianças (62 meninos e 58 meninas), com idades entre 8 e 10 anos, estudantes do $3^{\circ}$ ao $5^{\circ}$ ano do ensino fundamental, que foram selecionados através de questionário de recrutamento por gostarem e consumirem sorvete e caldo de cana, e também mediante autorização dos pais, através da assinatura do Termo de Consentimento Livre e Esclarecido, em atendimento a resolução do $\mathrm{CNS} \mathrm{n}^{\circ}$ 196/96. O projeto de pesquisa foi aprovado (CAAE 108.9712.6.0000.5188). Através do questionário de recrutamento também foram coletados dados sobre os hábitos de consumo de sorvete e caldo de cana desses julgadores. Os dados demográficos dos julgadores estão apresentados na Tabela 2.

Foram aplicados os testes sensoriais de aceitação utilizando escala hedônica facial de 7 pontos com âncoras verbais de horrível a ótimo, teste intenção de consumo e teste de ordenação-preferência.

Tabela 2. Dados demográficos dos julgadores $(n=120)$.

\begin{tabular}{llc}
\hline Características demográficas & & $\mathbf{( \% )}$ \\
\hline \multirow{2}{*}{ Gênero } & Masculino & $62(51,7 \%)$ \\
& Feminino & $58(48,3 \%)$ \\
Idade & 8 anos & $19(15,8 \%)$ \\
& 9 anos & $30(25,0 \%)$ \\
Escolaridade & 10 anos & $71(59,2 \%)$ \\
& $3^{\circ}$ ano & $21(17,5 \%)$ \\
& $4^{\circ}$ ano & $47(39,2 \%)$ \\
\hline
\end{tabular}

Fonte: Elaboração dos autores. 
No teste de açeitação e no de intenção de consumo, as amostras foram apresentadas de forma monádica e a ordem de apresentação das amostras entre os julgadores foi balanceada (DUTCOSKY, 2007; MINIM, 2010). Avaliou-se o grau de aceitação quanto aos atributos sensoriais cor, doçura e sabor, e a avaliação global.

Para o teste de ordenação-preferência foram apresentadas as três amostras em ordem balanceada para cada julgador e foi solicitado ordenar as amostras em ordem de preferência (DUTCOSKY, 2007; MINIM, 2010).

Os sorvetes foram servidos em copos descartáveis com capacidade para $50 \mathrm{~mL}$ codificados com números aleatórios de três dígitos; também foi servido copo com água para remoção do sabor residual entre as amostras (DUTCOSKY, 2007; MINIM, 2010). Os julgadores foram instruídos individualmente a respeito da realização dos testes com a leitura das fichas e explicação de cada teste e escalas utilizadas.

\section{Análise Estatística}

Os resultados das análises físico-químicas e dos testes sensoriais de aceitação foram analisados através da Análise de Variância (ANOVA) e teste de Tukey, a um nível de significância de 5\% (DUTCOSKY, 2007; MINIM, 2010), utilizando o software Assistat versão 7.6 beta (2011). A aceitação quanto aos atributos sensoriais cor, doçura e sabor, e avaliação global avaliados no teste hedônico e teste de intenção de consumo, foram construídos histogramas de distribuição. Foram calculadas as porcentagens de aceitação para os atributos sensoriais cor, doçura e sabor, e avaliação global, utilizando a classificação dos julgadores em função da faixa utilizada da escala hedônica (1-3="rejeição"; 4="neutro"; 5-7="aceitação"). O teste de ordenação-preferência foi analisado pelo teste de Friedman, utilizando a tabela de Newell e MacFarlane (DUTCOSKY, 2007; IAL, 2008), atribuindo os valores 1 (formulação de menor preferência) e 3 (formulação de maior preferência).

\section{Resultados e Discussão}

\section{Análise microbiológica}

Os sorvetes analisados apresentaram contagem de micro-organismos inferiores aos limites estabelecidos pela legislação brasileira (BRASIL, 2001), contagem de coliformes totais e termotolerantes $(<3,0 \mathrm{NMP} / \mathrm{g})$, Staphylococcus aureus coagulase positiva (ausência), Salmonella (ausência). Portanto, os sorvetes foram considerados aptos para consumo.

\section{Caracterização físico-química do sorvete}

A caracterização físico-química dos sorvetes elaborados com caldo de cana está apresentada na Tabela 3. Para os teores de umidade, cinzas, proteína, lipídios, carboidratos e açúcares totais não houve diferença significativa $(p \leq 0,05)$ entre as formulações. Os teores de açúcares redutores em lactose e não redutores em sacarose apresentaram diferença $(p \leq 0,05)$ entre as formulações. As formulações SC e SCM não diferiram entre si, mas diferiram de SCR. A adição de rapadura na formulação SCR contribuiu para o aumento de sacarose, com isso houve um aumento no teor de açúcar não redutor em sacarose e uma diminuição no teor de açúcar redutor em lactose, o que diferiu a formulação SCR das formulações SC e SCM. 
Tabela 3. Caracterização físico-química das formulações dos sorvetes de caldo de cana.

\begin{tabular}{lccc}
\hline \multirow{2}{*}{ Parâmetros } & \multicolumn{3}{c}{ Formulações } \\
\cline { 2 - 4 } & SC & SCM & SCR \\
\hline Umidade $(\mathrm{g} / 100 \mathrm{~g})$ & $69,33 \pm 0,05^{\mathrm{a}}$ & $68,93 \pm 0,42^{\mathrm{a}}$ & $68,38 \pm 0,28^{\mathrm{a}}$ \\
Cinzas $(\mathrm{g} / 100 \mathrm{~g})$ & $0,70 \pm 0,03^{\mathrm{a}}$ & $0,72 \pm 0,03^{\mathrm{a}}$ & $0,72 \pm 0,02^{\mathrm{a}}$ \\
Proteína $(\mathrm{g} / 100 \mathrm{~g})$ & $2,75 \pm 0,04^{\mathrm{a}}$ & $2,76 \pm 0,06^{\mathrm{a}}$ & $2,76 \pm 0,05^{\mathrm{a}}$ \\
Lipídeos $(\mathrm{g} / 100 \mathrm{~g})$ & $6,55 \pm 0,03^{\mathrm{a}}$ & $6,56 \pm 0,05^{\mathrm{a}}$ & $6,63 \pm 0,04^{\mathrm{a}}$ \\
Carboidratos $(\mathrm{g} / 100 \mathrm{~g})$ & $20,67 \pm 0,01^{\mathrm{a}}$ & $21,03 \pm 0,37^{\mathrm{a}}$ & $21,50 \pm 0,36^{\mathrm{a}}$ \\
VCT $(\mathrm{g} / 100 \mathrm{~g})$ & $152,63^{\mathrm{a}}$ & $154,25^{\mathrm{a}}$ & $156,75^{\mathrm{a}}$ \\
Açúcares redutores $(\mathrm{g} / 100 \mathrm{~g})$ & $8,43 \pm 0,72^{\mathrm{a}}$ & $8,64 \pm 0,41^{\mathrm{a}}$ & $6,01 \pm 0,15^{\mathrm{b}}$ \\
Açúcares não redutores $(\mathrm{g} / 100 \mathrm{~g})$ & $10,58 \pm 0,59^{\mathrm{b}}$ & $12,14 \pm 0,20^{\mathrm{b}}$ & $15,27 \pm 0,04^{\mathrm{a}}$ \\
Açúcares totais $(\mathrm{g} / 100 \mathrm{~g})$ & $19,01 \pm 0,31^{\mathrm{a}}$ & $20,78 \pm 0,01^{\mathrm{a}}$ & $21,28 \pm 0,18^{\mathrm{a}}$ \\
\hline
\end{tabular}

SC (sorvete de caldo de cana), SCM (sorvete de caldo de cana com mel de engenho), SCR (sorvete de caldo de cana com rapadura). As médias seguidas de letras iguais na mesma linha não diferem entre si pelo teste de Tukey a 5\% de significância. Média de três processamentos e três repetições. VCT = valor calórico total.

Fonte: Elaboração dos autores.

Os teores de lipídeos obtidos neste trabalho de $(6,55$ a $6,63 \mathrm{~g} / 100 \mathrm{~g})$ foram inferiores aos obtidos em sorvetes por Silva Junior e Lannes (2011) que obtiveram de (12,32 a 12,47 g/100 g) de lipídeos, porém, semelhantes aos obtidos por Pereira et al. (2012), que relataram valores de $(6,0$ a $6,06 \mathrm{~g} / 100$ g) de lipídeos em frozen yogurt de morango. Os sorvetes de caldo de cana apresentaram reduzido teor de gordura, comparável a gelados mais leves como os frozen yogurt, além de serem formulados com gordura de palma livre de trans, proporcionando um sorvete mais saudável.

Os valores de proteínas obtidas neste trabalho $(2,75$ a 2,76 g/100 g) foram inferiores aos relatados por Erkaya, Dagdemir e Sengül (2012), Pereira et al. (2012) e Rossa, Burin e Bordignon-Luiz (2012) que obtiveram concentrações de proteína de $(3,85$ a 5,$80 ; 3,77$ a 3,82 e 3,82 a $3,91 \mathrm{~g} / 100 \mathrm{~g}$, respectivamente). Isso ocorreu devido à utilização de soro de leite desmineralizado na produção dos sorvetes de caldo de cana, que não foi utilizado na produção dos sorvetes dos autores mencionados. De acordo com a RDC nº 269/2005, a ingestão diária recomendada (IDR), para crianças de 7 a 10 anos é de $34 \mathrm{~g}$ de proteína (BRASIL, 2005b) e os sorvetes de caldo de cana atendem a aproximadamente $8 \%$ das necessidades diárias de proteína desta faixa etária, em $100 \mathrm{~g}$ de sorvete.
Os valores de carboidratos de $(25,43$ a 27,23 g/100 g) obtidos por Silva Junior e Lannes (2011), foram um pouco acima aos obtidos neste trabalho $(20,67$ a 21,50 g/ 100 g). Essa variação é devido às diferenças nas formulações e aos adoçantes que foram utilizados em cada trabalho.

A quantificação dos minerais dos sorvetes elaborados com caldo de cana estão apresentados na Tabela 4. Os valores de cálcio (188,85 a 206,10 $\mathrm{mg} / 100 \mathrm{~g}$ ), fósforo $(173,40 \mathrm{a} 174,20 \mathrm{mg} / 100 \mathrm{~g}) \mathrm{e}$ ferro (2,0 a 2,12 mg/100 g), foram superiores aos dos sorvetes comuns industrializados, que apresentam aproximadamente 121,67 mg de cálcio, 105,67 mg de fósforo e $0,37 \mathrm{mg}$ de ferro em $100 \mathrm{~g}$ de sorvete (IBGE, 2009b). Esse aumento na quantidade de minerais nos sorvetes de caldo de cana ocorreu devido à substituição do açúcar pelo caldo de cana na formulação dos sorvetes, aumentando o seu valor nutricional.

De acordo com a RDC no 269/2005, a ingestão diária recomendada (IDR), para crianças de 7 a 10 anos é de $700 \mathrm{mg}$ de cálcio, $9 \mathrm{mg}$ de ferro e 1.250 $\mathrm{mg}$ de fósforo (BRASIL, 2005b), e os sorvetes de caldo de cana, em média, atendem a 28,5\%, 22,2\% e $14 \%$ destas necessidades diárias de cálcio, ferro e fósforo, respectivamente, em $100 \mathrm{~g}$ de sorvete. 
Tabela 4. Análise de minerais das formulações dos sorvetes de caldo de cana.

\begin{tabular}{lccc}
\hline \multirow{2}{*}{ Minerais } & \multicolumn{3}{c}{ Formulações } \\
\cline { 2 - 4 } & SC & SCM & SCR \\
\hline Cálcio $(\mathrm{mg} / 100 \mathrm{~g})$ & 206,10 & 204,10 & 188,85 \\
Ferro $(\mathrm{mg} / 100 \mathrm{~g})$ & 2,00 & 2,05 & 2,12 \\
Fósforo $(\mathrm{mg} / 100 \mathrm{~g})$ & 174,20 & 173,40 & 174,00 \\
Sódio $(\mathrm{mg} / 100 \mathrm{~g})$ & 176,00 & 176,00 & 177,00 \\
\hline
\end{tabular}

SC (sorvete de caldo de cana), SCM (sorvete de caldo de cana com mel de engenho), SCR (sorvete de caldo de cana com rapadura). Fonte: Elaboração dos autores.

A organização mundial de saúde (OMS) recomenda o consumo máximo de $2.000 \mathrm{mg}$ de sódio ao dia (BRASIL, 2013). Os sorvetes elaborados com caldo de cana apresentaram teores de sódio de (176,00 a $177,00 \mathrm{mg} / 100 \mathrm{~g})$. Em média, cada 100 $\mathrm{g}$ desses sorvetes possuem $8,85 \%$ da quantidade diária recomendada de sódio.
Caracterização dos hábitos de consumo das crianças

$\mathrm{Na}$ Figura 1a está ilustrada a frequência de consumo de sorvete entre as crianças que realizaram o teste, e verificou-se que $63 \%$ têm o hábito de consumir sorvete pelo menos uma vez ao mês. Os que consomem raramente foram $35 \%$ e os que nunca consomem apenas $2 \%$. Observando-se que o sorvete é um alimento bastante consumido entre as crianças que fizeram parte do estudo.

Figura 1. Frequência de consumo de (a) sorvete e (b) caldo de cana, entre as crianças que participaram do teste $(\mathrm{n}=$ 120 indivíduos).

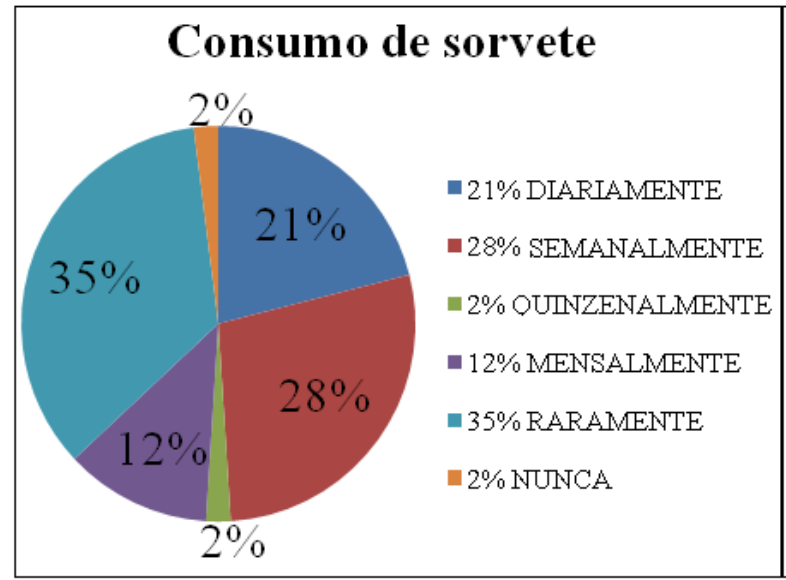

(a)

\section{Consumo de caldo de cana}

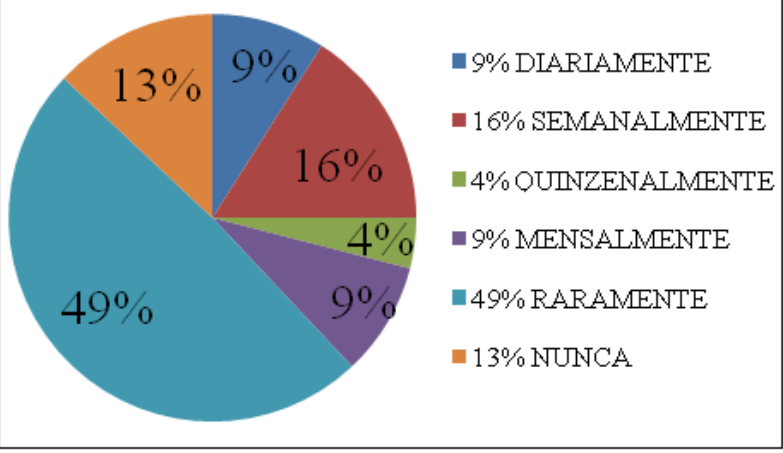

(b)

Fonte: Elaboração dos autores.

A frequência de consumo de caldo de cana pelas crianças que participaram da pesquisa é apresentada na Figura 1b. Observa-se que 13\% nunca consomem caldo de cana e $49 \%$ raramente. E que $29 \%$ consomem caldo de cana pelo menos uma vez ao mês. Nota-se, portanto um menor consumo de caldo de cana comparado ao do sorvete; este consumo pode ser elevado ao unir esses dois alimentos em um único produto. 


\section{Análise sensorial}

Os escores médios referentes ao teste hedônico com os sorvetes de caldo de cana estão apresentados na Tabela 5. As amostras das três formulações de sorvete de caldo de cana obtiveram boa aceitação, uma vez que todos os atributos sensoriais avaliados (cor, doçura, sabor) e aceitação global apresentaram escores médios acima de 6 (muito bom). Não houve diferença na aceitação $(\mathrm{p} \leq 0,05)$ entre as formulações em nenhum dos atributos sensoriais avaliados e aceitação global.

Tabela 5. Aceitação das formulações dos sorvetes de caldo de cana.

\begin{tabular}{cccccc}
\hline Formulações & Atributos/Aceitação & Média & Aceitação & Neutro & Rejeição \\
& Cor & $6,2 \pm 0,93^{\mathrm{a}}$ & $95,0 \%$ & $5,0 \%$ & $0,0 \%$ \\
$\mathrm{SC}$ & Doçura & $6,1 \pm 1,08^{\mathrm{a}}$ & $88,3 \%$ & $10,0 \%$ & $1,7 \%$ \\
& Sabor & $6,2 \pm 0,93^{\mathrm{a}}$ & $94,2 \%$ & $5,8 \%$ & $0,0 \%$ \\
& Avaliação global & $6,5 \pm 0,81^{\mathrm{a}}$ & $96,7 \%$ & $3,3 \%$ & $0,0 \%$ \\
\hline \multirow{4}{*}{$\mathrm{SCM}$} & Cor & $6,2 \pm 0,94^{\mathrm{a}}$ & $95,0 \%$ & $4,2 \%$ & $0,8 \%$ \\
& Doçura & $6,0 \pm 1,12^{\mathrm{a}}$ & $89,2 \%$ & $8,3 \%$ & $2,5 \%$ \\
& Sabor & $6,1 \pm 0,99^{\mathrm{a}}$ & $91,7 \%$ & $8,3 \%$ & $0,0 \%$ \\
& Avaliação global & $6,4 \pm 0,93^{\mathrm{a}}$ & $95,0 \%$ & $4,2 \%$ & $0,8 \%$ \\
\hline \multirow{3}{*}{$\mathrm{SCR}$} & Cor & $6,2 \pm 1,17^{\mathrm{a}}$ & $95,0 \%$ & $2,5 \%$ & $2,5 \%$ \\
& Doçura & $6,1 \pm 1,07^{\mathrm{a}}$ & $92,5 \%$ & $5,8 \%$ & $1,7 \%$ \\
& Sabor & $6,3 \pm 0,93^{\mathrm{a}}$ & $95,0 \%$ & $4,2 \%$ & $0,8 \%$ \\
& Avaliação global & $6,4 \pm 0,99^{\mathrm{a}}$ & $96,7 \%$ & $2,5 \%$ & $0,8 \%$ \\
\hline
\end{tabular}

SC (sorvete de caldo de cana), SCM (sorvete de caldo de cana com mel de engenho), SCR (sorvete de caldo de cana com rapadura). As médias seguidas de letras iguais na mesma linha não diferem entre si pelo teste de Tukey a 5\% de significância. Escala hedônica de 7 pontos (1= "horrível"; 4= "mais ou menos"; 7= "ótimo"). (n= 120 julgadores). Classificação dos julgadores em função da faixa utilizada da escala hedônica (1-3="rejeição"; 4="neutro"; 5-7="aceitação"). (n= 120 julgadores).

Fonte: Elaboração dos autores.

Na Figura 2, está apresentada a distribuição das notas atribuídas a cada formulação para cada atributo sensorial avaliado e avaliação global. Observa-se que a nota 7 (ótimo) foi atribuída por mais $50 \%$ dos julgadores. As formulações contendo apenas caldo de cana (SC), contendo caldo de cana e mel de engenho (SCM) e contendo caldo de cana e rapadura (SCR), respectivamente, foram avaliadas como "ótimo" por: 58(48,3\%), 61(50,8\%) e $65(54,2 \%)$ dos julgadores para o atributo cor; $55(45,8 \%), 58(48,3 \%)$ e $55(45,8 \%)$ dos julgadores para o atributo doçura; 62(51,7\%), 53(44,2\%) e $69(57,5 \%)$ dos julgadores para o atributo sabor e $76(63,4 \%), 74(61,7 \%)$ e $77(64,2 \%)$ dos julgadores para avaliação global.

$\mathrm{Na}$ Tabela 5 estão apresentadas as porcentagens de aceitação, de neutralidade e de rejeição dos sorvetes de caldo de cana. Observa-se que as porcentagens de aceitação de todas as formulações foram excelentes para todos os atributos sensoriais avaliados. As formulações contendo apenas caldo de cana (SC), contendo caldo de cana e mel de engenho (SCM) e contendo caldo de cana e rapadura (SCR), respectivamente, obtiveram índices de aceitação de 95,0\%, 95,0\%, 95,0\% para o atributo cor; $88,3 \%, 89,2 \%, 92,5 \%$ para o atributo doçura; $94,2 \%, 91,7 \%, 95,0 \%$ para o atributo sabor; $96,7 \%, 95,0 \%, 96,7 \%$ para a avaliação global. Os valores observados foram superiores aos relatados por Maia et al. (2008) em sorvetes com xilitol, em estudo sensorial com adultos, para os mesmos atributos sensoriais avaliados, que obteve índices de aceitação para os sabores nata, morango e chocolate, respectivamente de $75,0 \%, 89,0 \%$ e $86 \%$ para o atributo cor; $75,0 \%, 72,0 \%$ e $83,0 \%$ para o atributo doçura; $77,0 \%, 68,0 \%$ e $89,0 \%$ para o atributo sabor e $67,0 \%, 91,0 \%$ e $88,0 \%$ para a avaliação global. 
Figura 2. Histogramas de aceitação de (a) cor; (b) doçura; (c) sabor e (d) avaliação global dos sorvetes de caldo de cana.

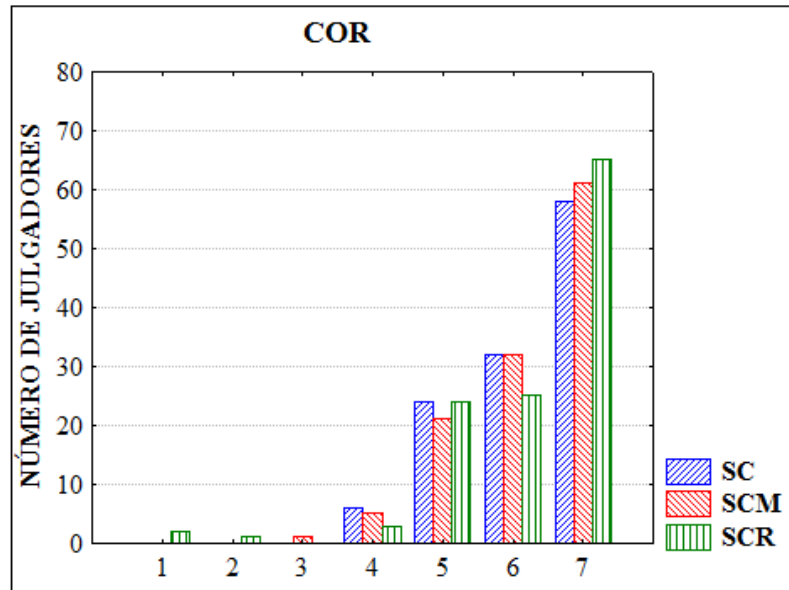

(a)

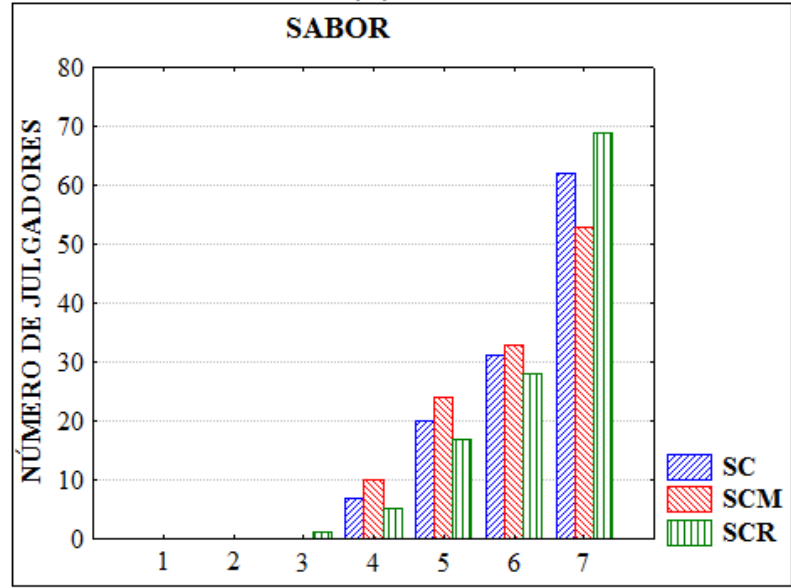

(c)

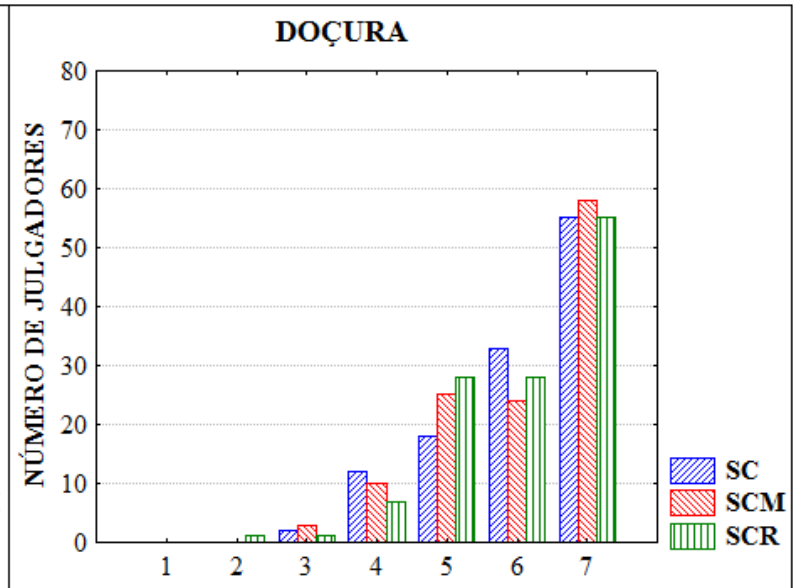

(b)

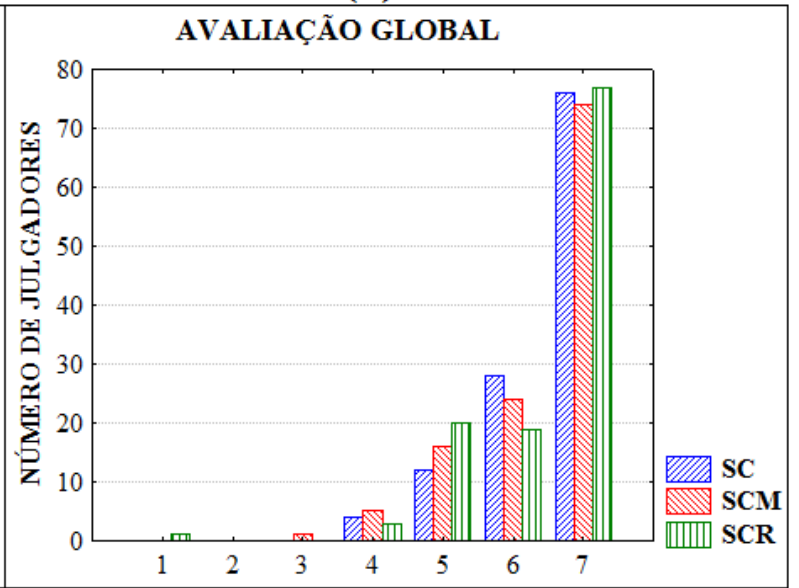

(d)

SC (sorvete de caldo de cana), SCM (sorvete de caldo de cana com mel de engenho), SCR (sorvete de caldo de cana com rapadura). Escala hedônica de 7 pontos (1= "horrível"; 4= "mais ou menos"; $7=$ "ótimo"). (n= 120 julgadores).

Fonte: Elaboração dos autores.

A intenção de consumo dos sorvetes de caldo de cana é apresentada na Figura 3. Observa-se que para todas as formulações, há uma maior concentração das notas entre "freqüentemente" e "sempre", comprovando que os sorvetes de caldo de cana obtiveram alta intenção de consumo pelos provadores. É observado que 77(64,2\%), 71(59,2\%) e $79(65,8 \%)$ dos provadores consumiriam "sempre" os sorvetes de caldo de cana das formulações contendo apenas caldo de cana (SC), contendo caldo de cana e mel de engenho (SCM) e contendo caldo de cana e rapadura (SCR), respectivamente, ou seja, mais de $60 \%$ dos julgadores afirmaram que consumiriam sempre qualquer uma das formulações do sorvete de caldo de cana.

O teste de ordenação-preferência (Tabela 6), indicou que não houve preferência significativa $(\mathrm{p}$ $\leq 0,05)$ por nenhuma das formulações de sorvete de caldo de cana. Todas as formulações foram preferidas pelos julgadores. 
Figura 3. Histograma de intenção de consumo dos sorvetes de caldo de cana.

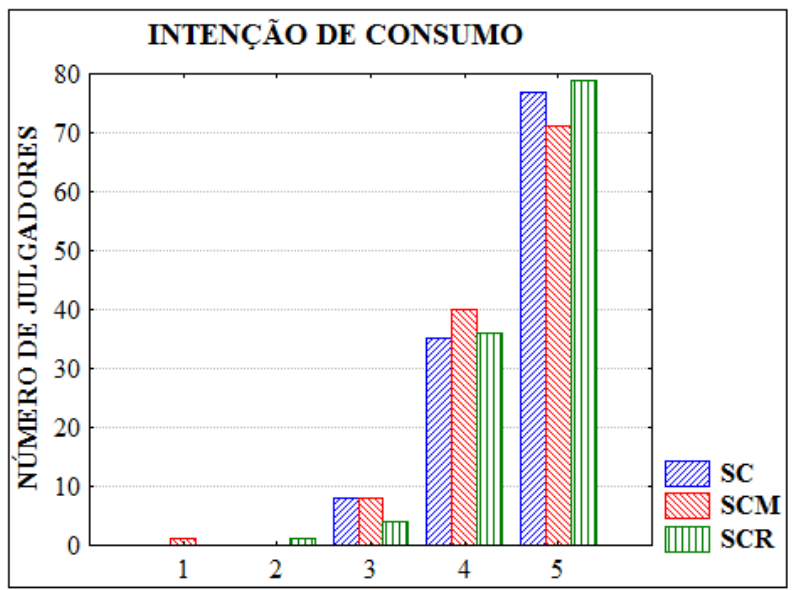

SC (sorvete de caldo de cana), SCM (sorvete de caldo de cana com mel de engenho), SCR (sorvete de caldo de cana com rapadura). Escala de 5 pontos (1="nunca"; $3=$ "talvez"; 5="sempre"). (n=120 julgadores).

Fonte: Elaboração dos autores.

Tabela 6. Totais de ordenação dos sorvetes de caldo de cana.

\begin{tabular}{cccc}
\hline \multirow{2}{*}{$\mathbf{N}^{\mathbf{0}}$ de julgadores } & \multicolumn{3}{c}{ Formulações } \\
\cline { 2 - 4 } & $\mathbf{S C}$ & SCM & SCR \\
\hline $\mathrm{n}=120$ & $247^{\mathrm{a}}$ & $223^{\mathrm{a}}$ & $253^{\mathrm{a}}$ \\
\hline
\end{tabular}

SC (sorvete de caldo de cana), SCM (sorvete de caldo de cana com mel de engenho), SCR (sorvete de caldo de cana com rapadura). Escala de ordenação: 1 (menor preferência) e 3 (maior preferência), ( $n=120$ julgadores).

Fonte: Elaboração dos autores.

\section{Conclusões}

A utilização do caldo de cana na formulação dos sorvetes elevou a quantidade de minerais, quando comparado aos sorvetes comuns. Portanto, os sorvetes de caldo de cana são nutritivos, fornecendo cálcio, ferro e fósforo; atendendo parte das necessidades de ingestão diária recomendada (IDR), para crianças de 7 a 10 anos.

Quanto à avaliação sensorial, todas as formulações dos sorvetes elaborados com caldo de cana foram aceitas sensorialmente pelas crianças, apresentando elevadas porcentagens de aceitação e intenção de consumo.

\section{Agradecimentos}

Os autores agradecem à Lazz Sorvetes e a CAPES.

\section{Referências}

ASSOCIAÇÃO BRASILEIRA DAS INDÚSTRIAS E DOSETOR DE SORVETES-ABIS. Produção e consumo de sorvetes no Brasil. Disponível em: <www.abis.com. br/estatistica_producaoeconsumodesorvetesnobrasil. htmL >. Acesso em: 20 ago. 2013.

ASSOCIATION OF OFFICIAL ANALYTICAL CHEMISTS - AOAC. Official methods of analysis. Washington D.C.: AOAC, 2000. 1018 p. 
AMERICAN PUBLIC HEALTH ASSOCIATION APHA. Compendium of methods for the microbiological examination of foods. 4. ed. Washington D.C.: APHA, 2001. 676 p.

ASSISTAT 7.6 BETA. Assistência estatística. DEAG - CTRN - Universidade Federal de Campina Grande, Campina Grande, 2011.

BRASIL. Ministério da Saúde. Agência Nacional de Vigilância Sanitária. Resolução - RDC n. ${ }^{0} 12$, de 2 de janeiro de 2001. Regulamento técnico sobre padrões microbiológicos para alimentos. Diário Oficial [da] União, Brasília, 10 jan. 2001, Seção 1, p. 45-53. Disponível em: <http://www.anvisa.gov.br>. Acesso em: 20 ago. 2013.

- Ministério da Saúde. Agência de Vigilância Sanitária. Resolução-RDC n. ${ }^{\circ}$ 266, de 22 de setembro de 2005a. Regulamento técnico para de gelados comestíveis e preparados para gelados comestíveis. Diário Oficial [da] União, Brasília, 23 set. 2005, Seção 1, p. 370-371. Disponível em: <http://www.anvisa.gov.br>. Acesso em: 20 ago. 2013.

- Ministério da Saúde. Agência de Vigilância Sanitária. Resolução - RDC n. ${ }^{\circ}$ 269, de 22 de setembro de 2005b. Regulamento técnico sobre a ingestão diária recomendada (IDR) de proteína, vitaminas e minerais. Diário Oficial [da] União, Brasília, 23 set. 2005, Seção 1, p. 372. Disponível em: <http://www.anvisa.gov.br>. Acesso em: 20 ago. 2013.

Ministério da Saúde. Coordenação-Geral de Alimentação e Nutrição. 2013. Disponível em: <http:// nutricao.saude.gov.br/sodio.php>. Acesso em: 20 ago. 2013.

DUTCOSKY, S. D. Análise sensorial de alimentos. 2. ed. rev. e ampl. Curitiba: Champagnat, 2007. 239 p.

ERKAYA, T.; DAGDEMIR, R.; SENGÜL, M. Influence of cape gooseberry (Physalis peruviana L.) addition on the chemical and sensory characteristics and mineral concentrations of ice cream. Food Research Internation, v. 45, n. 1, p. 331-335, 2012.

FAVA, A. R. Atletas ingerem garapa para repor energia. Jornal da UNICAMP, Campinas, ed. 250, maio, 2004. Disponível em: <http://www.unicamp.brl $>$. Acesso em: 20 ago. 2013.

FOOD AND DRUG ADMINISTRATION - FDA. Bacteriological analytical manual. Silver Spring: FDA, 2011. Disponível em: <http://www.fda.gov>. Acesso em: 20 ago. 2013.
GALVÃO, A. P. G. L. K. Produção de sorvetes funcionais formulados com xilitol. 2003. Dissertação (Mestrado em Ciências) - Instituto de Química. Universidade Federal do Rio de Janeiro, Rio de Janeiro.

INSTITUTO BRASILEIRO DE GEOGRAFIA E ESTATÍSTICA - IBGE. Pesquisa industrial 2009 - produto. Rio de Janeiro, v. 28, n. 2, 2009a. 208 p. Disponível em: <http://www.ibge.gov.br>. Acesso em: 20 ago. 2013.

. Tabela de composição nutricional dos alimentos consumidos no Brasil - pesquisa de orçamentos familiares 2008-2009. Rio de Janeiro, 2009b. Disponível em: <http://www.ibge.gov.br>. Acesso em: 20 ago. 2013.

INSTITUTO ADOLFO LUTZ - IAL. Métodos físicoquímicos para análise de alimentos. 4. ed. São Paulo: Instituto Adolfo Lutz, 2008. v. 1, 1020 p.

MAIA, M. C. A.; GALVÃO, A. P. G. L. K.; MODESTA, R. C. D; PEREIRA JUNIOR; N. Avaliação do consumidor sobre sorvetes com xilitol. Ciência e Tecnologia de Alimentos, Campinas, v. 28, n. 2, p. 341-347, abr./jun. 2008.

MINIM, V. P. R. Análise sensorial: estudos com consumidores. 2. ed. rev. e ampl. Viçosa, MG: Ed. UFV, 2010.308 p.

NOGUEIRA, F. S.; FERREIRA, K. S.; CARNEIRO JUNIOR, J. B.; PASSONI, L. C. Minerais em melados e em caldos de cana. Ciência e Tecnologia de Alimentos, Campinas, v. 29, n. 4, p. 727-731, out./dez. 2009.

PEREIRA, G. G.; RAFAEL, L. M.; GAJO, A. A.; RAMOS, T. M.; PINTO, S. M.; ABREU, L. R.; RESENDE, J. V. Influência do $\mathrm{pH}$ nas características físico-químicas e sensoriais de frozen yogurt de morango. Semina: Ciências Agrárias, Londrina, v. 33, n. 2, p. 675686, abr. 2012.

REZZADORI, K. Pasteurização térmica e com membranas do caldo de cana adicionado de suco de maracujá. 2010. Dissertação (Mestrado em Engenharia de Alimentos) - Universidade Federal de Santa Catarina, Florianópolis.

ROSSA, P. N.; BURIN, V. M.; BORDIGNON-LUIZ, M. T. Effect of microbial transglutaminase on functional and rheological properties of ice cream with different fat contents. LWT-Food Science and Technology, v. 48, n. 2, p. 224-230, 2012.

SILVA JUNIOR, E.; LANNES, S. C. S. Effect of different sweetener blends and fat types on ice cream properties. Ciência e Tecnologia de Alimentos, Campinas, v. 31, n. 1, p. 217-220, jan./mar. 2011. 
